\title{
Effect of a high-fibre diet on the feeding behaviour of fattening pigs
}

\author{
Konstanze E. Kallabis and Otto Kaufmann
}

Division of Animal Husbandry and Technology, Faculty of Agriculture and Horticulture, Humboldt-Universität zu Berlin, Germany

\begin{abstract}
The natural behavioural repertoire of the pig includes extensive foraging behaviour and long feeding times. Customary feed for growing pigs does not meet these requirements, resulting in unsatisfied feeding motivation. This may lead to behavioural disorders and reduces animal welfare. Studies on sows showed that by enhancing crude fibre content in the feed, satiety can be improved and the feeding motivation reduced. In growing pigs, however, studies are lacking, although abnormal behaviours are widespread. Therefore, we investigated the feeding behaviour of 56 castrated male pigs, who received either a standard compound feed or a high fibre feed containing lignocellulosis. High fibre pigs feed less often but longer times than control pigs. The feeding rate of high fibre pigs is clearly reduced, resulting in lower feed intake. Due to the composition of the fibrous feed, energy intake is less and crude fibre intake higher in high fibre pigs. Those animals have lower daily weight gain than control pigs, the feed conversion, however, does not differ between diets. Our results indicate that fibrous feed increases satiety in growing pigs. Sufficient satiety reduces foraging and feeding motivation and related behavioural problems. High fibre feed is therefore suitable to improve the welfare of fattening pigs.
\end{abstract}

Keywords: fattening pig, fibre, feeding behaviour, animal welfare

\section{Introduction}

Modern housing systems for pigs are designed to deliver maximum performance. At the same time, consumers more and more develop a sense for animal welfare and tend to require animal friendly housing systems.

A housing system can be acknowledged as animal friendly if it meets the animal's requirements regarding feed, shelter and physical functions and the possibility to perform species-specific behaviour (Hesse et al. 2000). The most prominent species-specific behaviour of pigs is foraging-related rooting (Graves 1984). In natural environments pigs spend major parts of the day engaged in feeding and related behaviours (Kittawornrat \& Zimmerman 2011). Although this is common knowledge, modern housing systems do almost entirely ignore this requirement on the pigs' environment.

The behavioural repertoire of the pig includes a large range of exploratory behaviours and a high motivation to forage and manipulate substrate (Day et al. 1995, Kittawornrat \& Zimmerman 2011). The feed is found and fed in small bouts, the feeding rate therefore low 
and the feed intake is rather continuous. Next to feed of animal origin, natural feed includes plants: roots and grasses that are often high in crude fibre (Graves 1984).

Customary feed stuff for growing pigs by contrast is calculated to meet the nutritional requirements of the animal for best fattening results. It is mostly fed in short times without requiring any effort of gaining it. The level of crude fibre is low to ensure high energy content and good digestibility of the diet. This does not meet the pig's requirement for a long occupation with feeding. Also, customary housing systems are mostly barren and do not provide much opportunity for occupation. Unable to satisfy their motivation to forage, many pigs develop behavioural disorders, which can be seen as indicators for lacking welfare. When strongly developed, this can result in stereotypies like sham chewing or stereotypic locomotive behaviour (Day et al. 1995, Bergeron et al. 2000). Manipulative behaviours are also often misdirected against pen mates (Van Putten \& Dammers 1976), resulting in tail biting or vulva biting and causing severe damage to the animals.

In order to prevent such misbehaviours in pigs, different approaches are used. The suspected 'boredom' of pigs can be counteracted with improved enrichment of the pen. For instance, numerous studies showed that pigs kept on straw bedding, although they were more active in general, showed less stereotypies (Fraser et al. 1991, Spoolder et al. 1995, Peeters et al. 2006, Day et al. 2008, Jordan et al. 2008). This could be shown both for adult sows and for growing pigs. Straw bedding does not only occupy the pigs as a manipulative substrate but does also have a dietary effect when eaten (Tuyttens 2005). It was shown in different studies that not only a lack of opportunities to manipulate but also pure hunger leads to enhanced foraging motivation (Kelley et al. 1980, Day et al. 1995, Stern \& Andresen 2003). Hunger in pigs can be caused by restrictive feeding, as often practised in sow management (De Leeuw et al. 2008). A higher level of satiation can reduce activity and manipulative behaviours in pigs (De Leeuw \& Ekkel 2004, Bolhuis et al. 2010). This can be achieved by enhancing the level of crude fibre in the feed (Lee \& Close 1987).

The beneficial effects of high-fibre feedstuffs have been shown in several studies. Also the feeding behaviour of pigs is influenced by fibrous feedstuffs. Various authors report an increase of eating time (Robert et al. 1997, Ramonet et al. 1999, Danielsen \& Vestergaard 2001, Robert et al. 2002) and a reduced feeding rate (Ramonet et al. 1999, Meunier-Salaün et al. 2001). Guillemet et al. (2006) showed that fibrous feedstuff received during the pregnancy influenced the sows feeding strategy and lead to more but smaller meals during lactation, even if the content of fibre is reduced again. In this context, also reduced foraging and manipulation was observed (Robert et al. 1997, Braund et al. 1998, Danielsen \& Vestergaard 2001) as well as reduced aggression and stereotypies and other non-feeding oral behaviours (Ramonet et al. 1999, Whittaker et al. 1999, Bergeron et al. 2000, Danielsen \& Vestergaard 2001, Robert et al. 2002).

Most of these authors explain this effect by reduced hunger and a reduced motivation to forage, due to a higher satiation. However, not all authors found a beneficial effect of high fibre feed on animal welfare (McGlone \& Fullwood 2001, Holt et al. 2006).

The impact of fibrous feed on the feeding behaviour was almost exclusively studied on sows. The effect of fibrous feed on the feeding behaviour of growing pigs is not yet closely investigated. However, behavioural disorders in fattening pigs are just as widespread as in sows. Due to the positive impact of fibre on the welfare of sows, we believe that also in 
growing pigs a beneficial effect might be found. Therefore, in this paper we investigate the effect of a high-fibre feed on the feeding behaviour of growing pigs. We analyse effects on the frequency and duration of feeding events as well as feed intake and feeding rate, crude fibre and energy intake and feed conversion.

\section{Material and methods}

\section{Animals and experiments}

Two consecutive experiments A and B were conducted on 28 Duroc $\times$ (Landrace $\times$ Large White) castrated male pigs each, from March to July (A) and from September to December (B) 2010. Prior to each experiment was an adaption period of two weeks. In the beginning of each experiment, the animals were randomly assessed to two groups of 14 pigs of the same medium body weight (A: $23.0 \pm 2.6 \mathrm{~kg}, \mathrm{~B}: 40.1 \pm 4.2 \mathrm{~kg}$ ). Data collection ended after $96(\mathrm{~A})$ or 84 (B) days with a medium live body weight of $106.3 \pm 9.8 \mathrm{~kg}(\mathrm{~A})$ or of $103.3 \pm 12.7 \mathrm{~kg}(\mathrm{~B})$.

While the control group was fed ad libitum with a standard fattening compound feed, the test group's feed contained $6 \%$ lignocellulosis in experiment $A$ and $9 \%$ lignocellulosis in experiment $B$ and was thus higher in crude fibre (Table 1). The product used was Arbocel $R$ (J. Rettenmaier \& Söhne, Rosenberg, Germany). The manufacturer's recommendation is up to $3 \%$ for fattening pigs. We used the double and triple amount to ensure measurable results.

Table 1

Ingredient and nutrient composition of the control feed and the test feed

\begin{tabular}{lccc}
\hline & Standard feed & High-fibre feed A & High-fibre feed B \\
\hline Dry matter, \% & 86.76 & 87.30 & 87.57 \\
Ingredient composition, g/kg & & 379 & 349 \\
Wheat & 439 & 150 & 150 \\
Rye bran & 150 & 120 & 120 \\
Wheat bran & 120 & 80 & 80 \\
Barley & 80 & 75 & 75 \\
Rape cake & 75 & 66 & 66 \\
Soybean extraction meal & 66 & 30 & 30 \\
Sugar beet molasses & 30 & 17 & 17 \\
Rye & 17 & 60 & 90 \\
Lignocellulosis & - & & 5.04 \\
Nutrient composition, $\%$ dry matter & & 5.07 & 2.86 \\
Ash & 5.13 & 2.90 & 17.86 \\
Nitrogen & 2.98 & 18.12 & 8.39 \\
Protein & 18.64 & 7.33 & 2.05 \\
Crude fibre & 5.18 & 2.16 & 28.99 \\
Crude fat & 2.37 & 26.80 & 11.54 \\
Neutral detergent fibre & 22.42 & 9.98 & 3.45 \\
Acid detergent fibre & 6.86 & 3.16 & 11.58 \\
Acid detergent lignin & 2.09 & 11.92 & \\
Energy, ME MJ/kg & 12.6 & & \\
\hline
\end{tabular}

The pigs were housed in two similar outdoor enclosures. Each enclosure contained an automatic feeder and an automatic drinker as well as an air conditioned hut with slatted 
floor that served as resting area. The feeders were equipped with a sensor-based recognition tool for data acquisition. Each pig carried an ear-plug responder that allowed individual recognition at the feeder and the recording of time and amount of feeding.

During the experiments, enclosures were changed between groups once after 6 weeks (A) or every three weeks (B). The live body weight of all pigs was collected once per week.

\section{Data processing}

Due to illnesses and losses of animals, 11 to 13 pigs per group were analysed.

The data were transferred into a database and filtered for logical sequence, visits at the feeders with no or negative feed intake were deleted. Sums for each day and animal were calculated for the following properties: feeding duration, feeding frequency, feed intake and feeding rate.

Visits at the feeder were grouped into meals. Like various other behaviours, feeding behaviour can be split into bouts (Slater \& Lester 1982). The intervals between bouts were plotted as a log survivorship function, as described by Bigelow \& Houpt (1988). In accordance with the findings of Morgan et al. (2000), we found, however, a trimodal distribution and thus used a three-curve model.

For each group a pooled meal criterion was calculated, and the number of meals was assessed for each animal and day. Subsequently, the average feeding duration per meal and feed intake per meal were calculated by dividing daily sums by the number of meals. In addition, the daily intake of energy and crude fibre was assessed for each pig. Furthermore, daily feed efficiency was calculated for each pig by dividing feed intake by weight gain.

All data was assessed to one of three weight categories according to the body weight of the animal. Categories were I: $25-49.5 \mathrm{~kg}$, II: $50-79.5 \mathrm{~kg}$ and III: $80-125 \mathrm{~kg}$ (Table 2). Not all animals, however, started with an initial weight of $25 \mathrm{~kg}$ or reached a maximum weight of $125 \mathrm{~kg}$.

Table 2

Body weight categories and groups

\begin{tabular}{|c|c|c|c|c|c|c|c|c|c|c|c|c|}
\hline & \multicolumn{4}{|c|}{1} & \multicolumn{4}{|c|}{ II } & \multicolumn{4}{|c|}{ III } \\
\hline Weight range, kg & \multicolumn{4}{|c|}{$25-49.5$} & \multicolumn{4}{|c|}{$50-79.5$} & \multicolumn{4}{|c|}{$80-125$} \\
\hline Experiment & A & & & B & $A$ & A & & B & A & & B & B \\
\hline Group & control & test & control & test & control & I test & control & I test & control & test & control & test \\
\hline Sample size & 417 & 416 & 219 & 272 & 371 & 362 & 415 & 459 & 319 & 235 & 367 & 341 \\
\hline Mean weight, kg & 35.5 & 36.0 & 43.4 & 42.7 & 63.8 & 63.5 & 64.9 & 64.0 & 94.8 & 91.8 & 94.7 & 92.4 \\
\hline
\end{tabular}

The presentation of the results was mostly done by the use of Box-Whisker-Plots (Figures $2-8)$. In this form of diagram, the median is indicated by a horizontal line within the box. The box itself includes the lower and the upper quartile (25th and 75th percentile); and the whiskers indicate the sample minimum and sample maximum.

All properties were tested for significant differences between control and test group within weight categories, using the Mann-Whitney-U-Test. Software used for data processing and statistics was Microsoft Excel 2003, Microsoft Access 2003 (Microsoft, Redmond, WA, USA), KyPlot 5.0 (KyensLab Inc., Tokyo, Japan) and SPSS 18.0 (SPSS Inc., Chicago, IL, USA). 


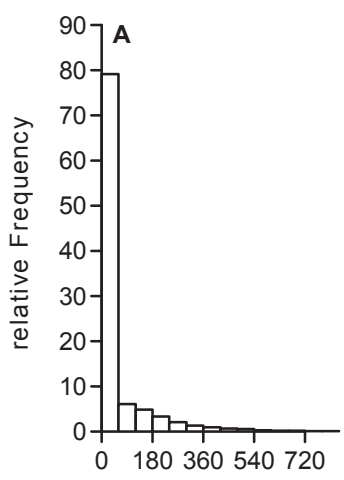

Minutes interval length

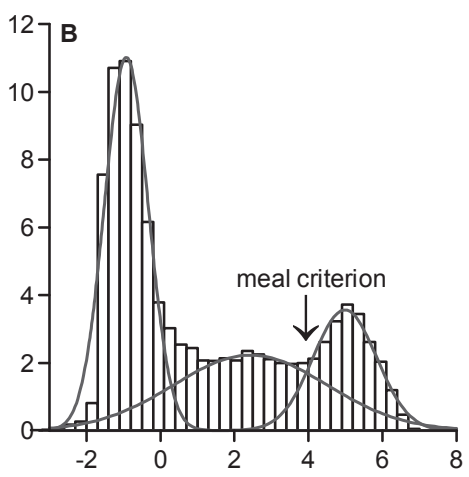

Log interval length

Figure 1

Probability density of the interval length (minutes) of the pauses between visits at the feeder ( $A$ ) and the logtransformed interval length with log-normal model (B) for the pooled data of all pigs from the control group of experiment $A$.

$\square \quad$ control group $\square \quad$ test group
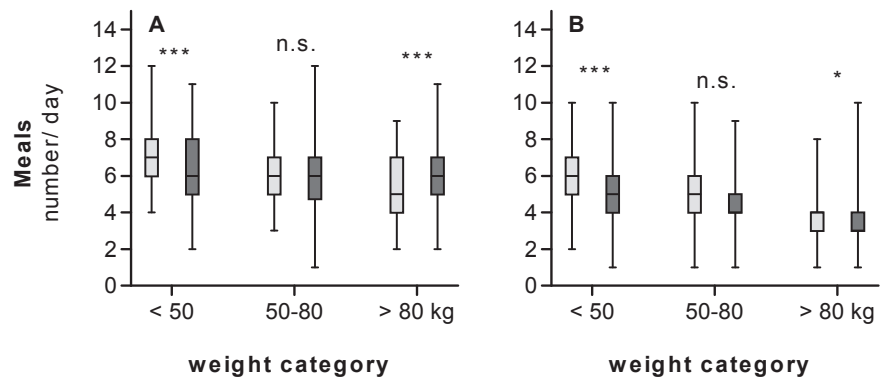

Figure 2

Mean number of meals per day of the test group and the control group in $A$ : experiment $A$ and $B$ : experiment B. Values are significantly different between diets: ${ }^{*} P<0.05$, ${ }^{*}{ }^{*} P<0.001$, ns: not significantly different

$\square$ control group $\square \quad$ test group
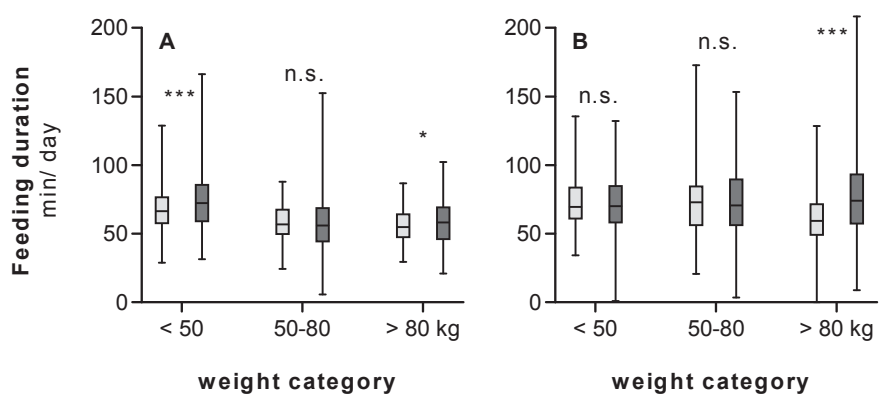

Figure 3

Mean feeding duration per day of the test group and the control group in experiment $A(A)$ and experiment $B(B)$. Values are significantly different between diets: ${ }^{*} P<0.05$, ${ }^{*}{ }^{*} P<0.001$, ns: not significantly different 


\section{Results}

The feeding behaviour of four groups of total 48 fattening pigs was analysed during the whole fattening period by assessing the following parameters per day: number of visits at the feeder, number of meals, feeding duration during the whole day, feeding duration during a meal, feed intake during the whole day and during a meal, feeding rate, energy intake, crude fibre intake and feed conversion. Values of the two test groups were compared with those of the control groups.

The number of visits at the feeder is strongly dependent on technical aspects and can underlay great variations. More meaningful is the number of meals. A meal consists of several feeding bouts that are separated by pauses of different length.

By applying the meal criterion based on the method described by Bigelow \& Houpt (1988), visits at the feeder were grouped into meals. A pooled meal criterion was calculated for each group of pigs. Figure 1 shows the untransformed and log-transformed data of intervals between feeder visits for the control group of experiment A. Pauses longer than the meal criterion separate two meals, while pauses shorter than the meal criterion separate two feeding bouts of the same meal. The meal criteria in experiment A were 50.91 min for the control group and $46.53 \mathrm{~min}$ for the test group, and in experiment B $72.09 \mathrm{~min}$ for the control group and $78.33 \mathrm{~min}$ for the test group.

\section{Feeding frequency}

The pigs of the test group tended to have fewer meals than those of the control group (Figure 2). This difference is highly significant in weight category I of both experiments. No significant difference can be seen in the body weight categories II, although the number of meals was less in the test group. The picture in body weight category III is diverse: while in experiment $B$ the test group again had significantly fewer meals than the control group, in experiment $A$ the test group had highly significantly more meals.

All groups showed a decreasing number of meals with growing weight, with the exception of the test group in experiment $A$, whose meal number increased in the highest weight category.

\section{Feeding duration}

The total time spend feeding during a day, as shown in Figure 3, was higher in the test group in most weight categories. This difference is significant in category I and III of experiment A and in category III of experiment B.

A change of daily feeding time with increasing body weight could not be observed.

The feeding duration per meal showed a similar pattern. Pigs of the test group fed longer per meal, this being statistically significant in the categories I and category III $\mathrm{B}(P<0.001)$. Differences in the categories II were not significant. Due to the higher number of meals of the test group of category III A, the feeding duration per meal in this group was significantly less than in the control group $(P<0.05)$.

While the average feeding duration per meal was the same for all weight categories in experiment $A$, in experiment $B$ it increased with increasing body weight of the animals. 

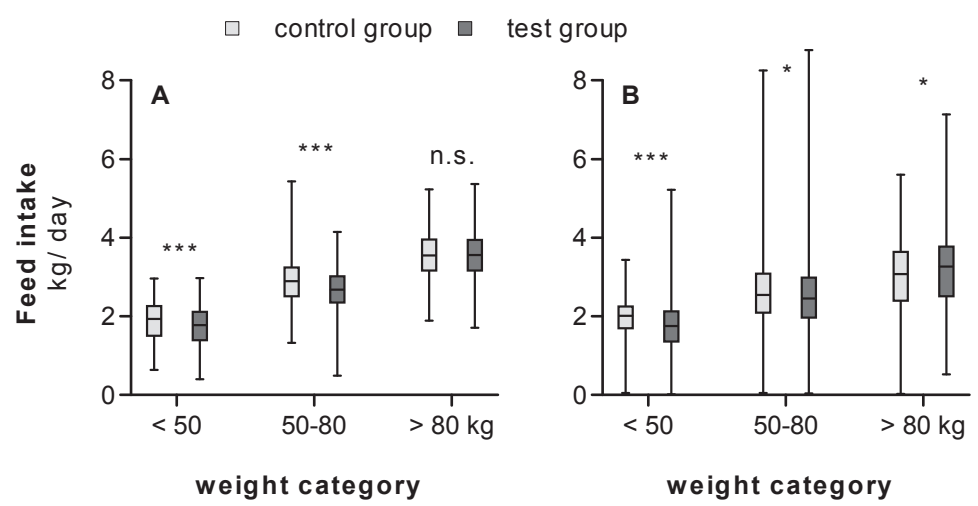

Figure 4

Mean daily feed intake of the test group and the control group in experiment $A(A)$ and experiment $B(B)$. Values are significantly different between diets: ${ }^{*} P<0.05,{ }^{* * *} P<0.001$, ns: not significantly different
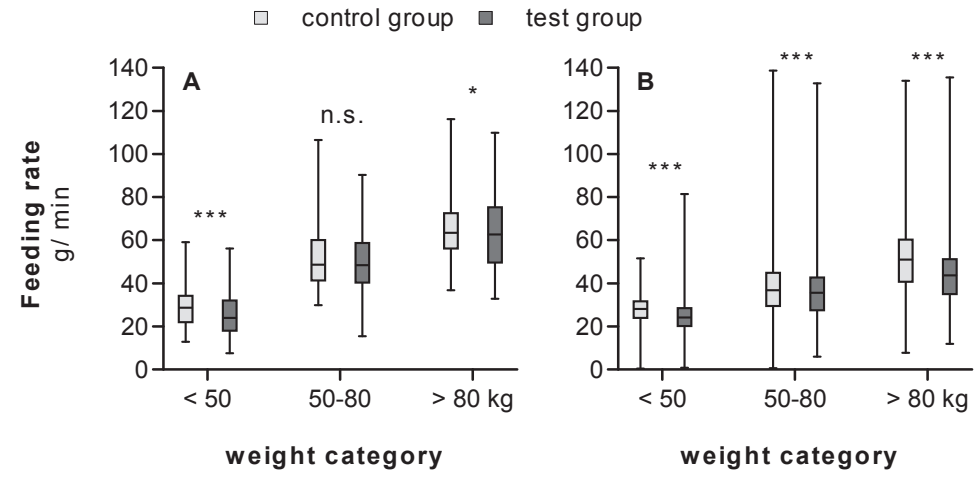

Figure 5

Mean feeding rate, feed intake per minute plotted against day of experiment, of the test group and the control group in experiment $A(A)$ and experiment $B(B)$. Values are significantly different between diets: ${ }^{*} P<0.05$, ${ }^{* * *} P<0.001$, ns: not significantly different
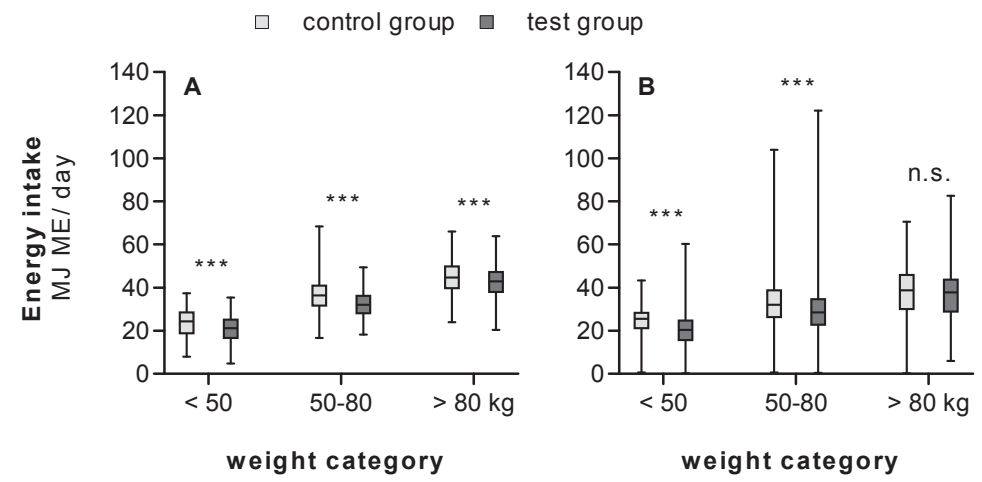

Figure 6

Mean daily energy intake of the test group and the control group in experiment $A(A)$ and experiment $B(B)$. Values are significantly different between diets: ${ }^{* *} P<0.001$, ns: not significantly different 


\section{Feed intake}

The daily feed intake of the high fibre test group is less than that of the control group in all categories but one (Figure 4). In the categories I and II this difference is statistically significant. Only pigs of the high fibre test group in category III in experiment B are feeding significantly more than the control pigs. Feed intake is clearly increasing during the fattening period.

While the daily feed intake was different between test group and control group, the feed intake per meal did not clearly differ between diets. Test groups fed significantly less per meal in category II $(P<0.05)$ and category III $(P<0.001)$ of experiment $A$, but more in category III of experiment $B(P<0.05)$. In all other categories, no differences could be observed. Due to decreasing meal numbers in the course of the experiment and increasing daily feed intake, the feed intake per meal was considerably increasing during the fattening period.

Figure 5 shows the feeding rate, that means the feed intake per minute. It did also distinctly increase during both experiments. The feeding rate of the high fibre test group is significantly lower than that of the control group. Only in category III A, this difference is not significant.

In consistence with the growing feed intake, the energy intake is also increasing during the fattening period (Figure 6). Energy intake of the control group is significantly higher than that of the test group, only in category III B this difference is not significant. In body weight category l, control pigs receive $14 \%$ and $24 \%$ more energy than high-fibre pigs, in category II $13 \%$ and $12 \%$ more and in category III $6 \%$ and $4 \%$ more energy.

Due to the higher content of crude fibre in the feed, crude fibre intake was significantly higher in the test group in all categories $(P<0.001)$, between $31 \%$ and $69 \%$.

As feed intake did increase during the fattening period, so did crude fibre intake.

\section{Weight gain and feed conversion}

Figure 7 shows the mean body weight gain of the high fibre test pigs and the control pigs. Starting with the same mean weight, high fibre pigs grew more slowly and weighed considerably less in the slope of the experiments. Mean daily weight gain of all categories was 822 and $697 \mathrm{~g} /$ day in the high fibre groups $A$ and B and 874 and $812 \mathrm{~g} /$ day in the control groups. Daily weight gain was significantly less in the test group in all weight categories, with the exception of category III in experiment A.

The feed efficiency, the expended feed per kg body weight gain of the pig, is shown in Figure 8. There is no significant difference to be observed between test group and control group in experiment $A$ as well as in the first two categories of experiment B. Only in category III B the efficiency of the test group is significantly higher. 

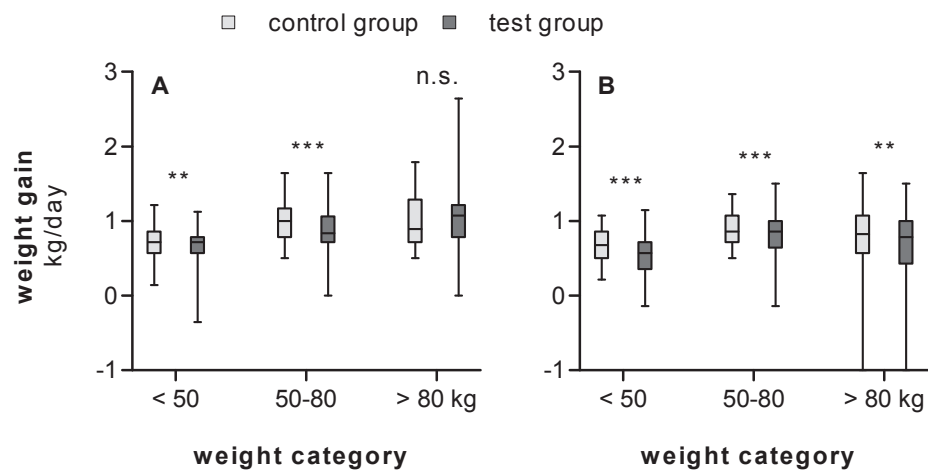

Figure 7

Mean daily weight gain of the test group and the control group in experiment $A(A)$ and experiment $B(B)$. Values are significantly different between diets: ${ }^{*} P<0.01,{ }^{* * *} P<0.001$, ns: not significantly different

$\square$ control group $\square \quad$ test group
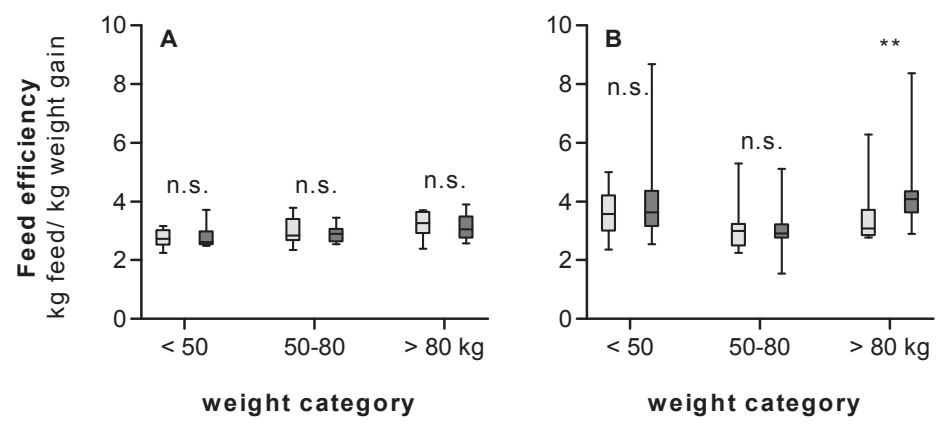

Figure 8

Mean feed efficiency of the test group and the control group in experiment $A(A)$ and experiment $B(B)$. Values are significantly different between diets: ${ }^{*} P<0.01$, ns: not significantly different

\section{Discussion}

The influence of high amounts of crude fibre in the feed on adult sows has been shown in several studies. Here we found similar impacts on the feeding behaviour of growing pigs.

The most prominent differences between high fibre and control pigs were a tendency for fewer meals in high fibre pigs, a longer daily feeding duration as well as longer feeding durations within a meal, a smaller amount of daily feed intake but no differences in feed intake per meal and a reduced feeding rate in high fibre pigs. While the daily energy intake of high fibre pigs was lower than that of the control group, the intake of crude fibre was higher. High fibre pigs had a lower daily weight gain during the experiment, the feed efficiency, however, was similar between groups.

We calculated meal criteria for each group of pigs between 46 and $78 \mathrm{~min}$. Most authors using the meal criterion found much smaller values, for example 2 min (Quiniou et al. 2000), 5 min (Renaudeau et al. 2003), 10 min (Bigelow \& Houpt 1988) or 28.3 min (Hyun et al. 1997). 
All these criteria are, however, based on a two-curve model, while we used a three-curve model as described by Morgan et al. (2000). The values above show that meal criteria vary strongly between experiments and are highly dependent on the experimental design and feeding regime. As Renaudeau et al. (2003) noted, has an overestimation of the meal criterion a negligible effect on the feeding pattern, while an underestimation may result in an increase in the number of meals that strongly influences further results.

The influence of meal number on all other values calculated per meal becomes apparent in the results for the weight category III (>80 kg) of experiment A. Contrary to the other results, the test group in this category show significantly more meals than the control group. As a result of this high meal number, the feeding duration and intake per meal is lower than expected by the other results.

In this experiment, high fibre pigs of all groups ingested significantly more crude fibre than the control pigs. Energy intake was less in all high-fibre groups.

Fibrous feed is supposed to increase satiety in pigs. The changes in feeding behaviour are therefore believed to be consequences of enhanced satiety.

The finding that high fibre pigs eat in fewer meals per day is in accordance with that. A higher and longer satiation reduces the motivation to feed for a longer time and thus increases the intervals between meals, which leads to fewer meals per day. We found mean meal numbers of 3.5 to 7 meals per day, similar to the numbers given by Hyun et al. (1997) and Quiniou et al. (2000), who fed barrows with customary fattening feed.

The calculated mean feed intake per meal in our two experiments is approximately $280 \mathrm{~g}$ and $380 \mathrm{~g}$ in weight category 1 and $510 \mathrm{~g}$ and $640 \mathrm{~g}$ in weight category II. That is more than reported by Quiniou et al. (2000), who calculated intakes of $261 \mathrm{~g}$ per meal for a group comparable to our first two weight categories.

Higher satiation and a higher gut fill can also been seen as a reason for the reduced daily feed intake of the high fibre groups (Danielsen \& Vestergard 2001). The feed intake per meal, however, did not vary considerably between groups. Presumably pigs finish their meal when they have fed a certain amount of feed and are satiated for the moment. This amount is not dependent on crude fibre level. The shorter satiation caused by low fibre feed prompts the control pigs to start their next meal sooner than high fibre pigs, leading to a higher meal number and higher daily feed intake.

The mean feeding rate of our small category I pigs is 24.5 to $28.7 \mathrm{~g} \mathrm{~min}^{-1}$ and rises up to $65.8 \mathrm{~g} \mathrm{~min}^{-1}$ in finishing category III pigs. Other authors found similar feeding rates of 23.6 (Hyun et al. 1997) or 31.3 to $42.4 \mathrm{~g} / \mathrm{min}$ (Quiniou et al. 2000) for pigs of body weights comparable to our categories I and II.

A clear result is the reduced feeding rate of high fibre pigs. Our findings are in accordance with the reports of Ramonet et al. (1999) who found $40 \%$ reduced feeding rates in restricted fed sows that received various fibre sources. This reduction of the feeding rate can explained with a diminished feeding motivation as well as a longer mastication time (Meunier-Salaün et al. 2001).

Due to the slower process of feeding, the feeding duration is clearly increased in high fibre pigs. This can be seen as well in daily feeing durations as in feeding durations within a meal. Longer feeding durations for high fibre pigs can also be found in studies on adult females. Robert et al. $(1997,2002)$ found an increase of the feeding duration of $100-200 \%$ in gilts that 
were fed with fibre of various sources. Ramonet et al. (1999), Danielsen \& Vestergaard (2001) and Holt et al. (2006) found a prolonged eating time in pregnant sows. In these studies, high fibre pigs received greater meals to ensure the same nutrient intake of all animals. However, magnification of feeding duration was higher than that of meal size.

Longer feeding times for high fibre feed result in longer occupation of the animal and might reduce the pigs' feeding motivation (Robert et al. 1997). Daily feeding times for barrows fed ad libitum are 67 to $78 \mathrm{~min}$ in literature (Hyun et al. 1997, Quiniou et al. 2000), similar than our findings of 55 to $74 \mathrm{~min}$ per day. Also our feeding times per meal of 10 to $24 \mathrm{~min}$ agree with the study of Hyun et al. (1997), who report 10.8 min mean feeding time per meal.

Not all studies, however, found a significant difference in the feeding behaviour of pigs fed with high fibre feedstuffs. Renaudeau et al. (2003) investigated the influence of wheat bran as fibre source on sows in tropical climate and concluded that feeding behaviour was not influenced by fibre content.

Fibrous feed for growing pigs is usually associated with insufficient performance. In this experiment, high fibre pigs had lower daily weight gain than the control pigs, as it was expected due to the lower energy content of the test feed. Only in the end of experiment A, daily weight gain did not differ between control and high fibre pigs, possibly because older pigs are not that sensitive to high amounts of crude fibre any more.

A longer fattening period of pigs fed with fibrous feed can therefore be expected. The feed efficiency, however, did not significantly differ between test group and control group.

To gain measurable results, we used rather high amounts of fibrous feed additive: double and triple of the amount recommended by the manufacturer. It seems likely that the recommended amount will not have such a strongly limiting effect on performance as it occurred in our experiments. It needs to be investigated if the beneficial effects of fibre do also apply for smaller concentrations. However, it was not the aim of this study to analyse the possibilities of economic use of fibrous feed but the impact on animal behaviour. An additional investigation on the economic efficiency of high fibre feed for fattening pigs would thus be advisable.

It can be summarised that high fibre pigs feed less often but longer times than control animals. However, due to reduced feeding rate, the feed intake is less in high fibre pigs. The composition of the test feed leads to the intake of less energy but more crude fibre. Test pigs gained less weight during the experiment, the feed efficiency, however, does not differ between diets.

The change of feeding behaviour in high fibre fed growing pigs gives strong evidence that fibrous feed enhances satiety. Higher satiety apparently leads to a reduced feeding motivation (Meunier-Salaün et al. 2001, Robert et al. 1997). Unsatisfied feeding motivation is known to lead to enhanced oral behaviour and as a result cause behavioural disorders and misdirected foraging behaviours in pigs. By reducing the feeding motivation as well as the motivation for other oral behaviours in pigs, the welfare of the animal can be improved. Fibrous feedstuff is therefore suitable to improve the wellbeing of growing pigs. To evaluate the economic efficiency of such a feed, further investigation will be necessary. 


\section{References}

Bergeron R, Bolduc J, Ramonet Y, Meunier-Salaün MC, Robert S (2000) Feeding motivation and stereotypies in pregnant sows fed increasing levels of fibre and/or food. Appl Anim Behav Sci 70, 27-40

Bigelow JA, Houpt TR (1988) Feeding and Drinking Patterns in Young Pigs. Physiol Behav 43, 99-109

Bolhuis JE, van den Brand H, Bartels AC, Oostindjer M, van den Borne JJGC, Kemp B, Gerrits, WJJ (2010) Effects of fermentable starch on behaviour of growing pigs in barren or enriched housing. Appl Anim Behav Sci $123,77-86$

Braund JP, Edwards, SA, Riddoch I, Buckner LJ (1998) Modification of foraging behaviour and pasture damage by dietary manipulation in outdoor sows. Appl Anim Behav Sci 56, 173-186

Brouns F, Edwards SA, English, PR (1994) Effect of dietary fibre and feeding system on activity and oral behaviour of group housed gilts. Appl Anim Behav Sci 39, 215-223

Danielsen V, Vestergaard EM (2001) Dietary fibre for pregnant sows: effect on performance and behaviour. Anim Feed Sci Technol 90, 71-80

Day JEL, Kyriazakis I, Lawrence AB (1995) The effect of food deprivation on the expression of foraging and explorative behaviour in the growing pig. Appl Anim Behav Sci 42, 193-206

De Leeuw JA, Bolhuis JE, Bosch G, Gerrits WJJ (2008) Effects of dietary fibre on behaviour and satiety in pigs. Proc Nutr Soc 67, 334-342

De Leeuw JA, Ekkel ED (2004) Effects of feeding level and the presence of a foraging substrate on the behaviour and stress physiological response of individually housed gilts. Appl Anim Behav Sci 86, 15-25

Graves HB (1984) Behaviour and Ecology of Wild and Feral Swine (Sus Scrofa). J Anim Sci 58, 482-492

Guillemet R, Dourmad JY, Meunier-Salaün MC (2006) Feeding behavior in primiparous lactating sows: Impact of a high-fibre diet during pregnancy. J Amin Sci 84, 2474-2481

Hesse D, Knierim U, von Borell E, Hermann HJ, Koch L, Müller C, Rauch HW, Sachser N, Zerbe F (2000) [Animal welfare on the test-bench, voluntary testing requirements in accordance with $\S 13 a$ of the Animal Protection Act]. DLG-Merkblatt 321 [in German]

Holt JP, Johnston LJ, Baidoo SK, Shurson GC (2006) Effects of a high-fiber diet and frequent feeding on behaviour, reproductive performance, and nutrient digestibility in gestating sows. J Anim Sci 84, 946-955

Hyun Y, Ellis M, McKeith FK, Wilson ER (1997) Feed Intake Pattern of Group-Housed Growing-finishing Pigs Monitored Using a Computerized Feed Intake Recording System. J Anim Sci 75, 1443-1451

Jordan D, Žgur S, Gorjanc G, Gorjanc G, Štuhec I (2008) Straw or hay as environmental improvement and its effect on behaviour and production traits of fattening pigs. Arch Tierz 51, 549-559

Kelley KW, McGlone JM, Gaskins, CT (1980) Porcine aggression: measurement and effects of crowding and fasting. J Anim Sci 50, 336-341

Kittawornrat A, Zimmerman JJ (2011) Toward a better understanding of pig behavior and pig welfare. Anim Health Res Rev 12, 25-32

Lee PA, Close WH (1987) Bulky Feeds for Pigs: A consideration of Some Non-Nutritional Aspects. Livest Prod Sci 16, 395-405

McGlone JJ, Fullwood SD (2001) Behavior, reproduction, and immunity of crated pregnant gilts: Effects of high fiber and rearing environment. J Anim Sci 79, 1466-1474

Meunier-Salaün MC, Edwards SA, Robert S (2001) Effect of dietary fibre on the behaviour and health of the restricted fed sow. Anim Feed Sci Technol 90, 53-69

Morgan CA, Emmans GC, Tolkamp BJ, Kyriazakis I (2000) Analysis of the feeding behavior of pigs using different models. Physiol Behav 68, 395-403

Peeters E, Driessen B, Moons CPH, Ödberg FO, Geers R (2006) Effect of temporary straw bedding on pigs' behaviour, performance, cortisol and meat quality. Appl Anim Behav Sci 98, 234-248

Quiniou N, Dubois S, Noblet J (2000) Voluntary feed intake and feeding behaviour of group-housed growing 
pigs are affected by ambient temperature and body weight. Livest Prod Sci 63, 245-253

Ramonet Y, Meunier-Salaün MC, Dourmad JY (1999) High-Fiber Diets in Pregnant Sows: Digestive Utilization and Effects on the Behavior of the Animals. J Anim Sci 77, 591-599

Renaudeau D, Weisbecker JL, Noblet J (2003) Effect of season and dietary fibre on feeding behaviour of lactating sows in tropical climate. Anim Sci 77, 429-437

Robert S, Rushen J, Farmer C (1997) Both energy content and bulk of food affect stereotypic behaviour, heart rate and feeding motivation of female pigs. Appl Anim Behav Sci 54, 161-171

Robert S, Bergeron R, Farmer C, Meunier-Salaün MC (2002) Does the number of daily meals affect feeding motivation and behaviour of gilts fed high-fibre diets? Appl Anim Behav Sci 76, 105-117

Slater PJB, Lester NP (1982) Minimising errors in splitting behaviour into bouts. Behaviour 79, 153-161

Spoolder HAM, Burbidge JA, Edwards SA, Simmins PH, Lawrence AB (1995) Provision of straw as a foraging substrate reduces the development of excessive chain and bar manipulation in food restricted sows. Appl Anim Behav Sci 43, 249-262

Stern S, Andresen N (2003) Performance, site preferences, foraging and excretory behaviour in relation to feed allowance of growing pigs on pasture. Livest Prod Sci 79, 257-265

Tuyttens FAM (2005) The importance of straw for pig and cattle welfare: A review. Appl Anim Behav Sci 92, 261-282

Van Putten G, Dammers J (1976) A comparative study of the well-being of piglets reared conventionally and in cages. Appl Anim Ethol 2, 339-356

Whittaker X, Edwards SA, Spoolder HAM, Lawrence AB, Corning S (1999) Effect of straw bedding and high fibre diets on the behaviour of floor fed group-housed sows. Appl Anim Behav Sci 63, 25-39

Young RJ, Carruthers J, Lawrence AB (1994) The effect of a foraging device (»The Edinburgh Foodball«) on the behaviour of pigs. Appl Anim Behav Sci 39, 237-247

Received 19 August 2011, accepted 8 February 2012.

Corresponding author:

Konstanze E. Kallabis

email: konstanze.kallabis@agrar.hu-berlin.de

Humboldt-Universität zu Berlin, Landwirtschaftlich-Gärtnerische Fakultät, Invalidenstr. 42, 10099 Berlin, Germany 